\title{
Opioid substitution treatment and disasters: perspectives from Aotearoa New Zealand
}

\author{
Denise Blake, Joint Centre for Disaster Research, Massey University, New Zealand
}

In Aotearoa New Zealand, disaster risk management (DRM) aspires to protect the lives and livelihoods of people and places. It does this by encouraging people and communities to be disaster ready, while ensuring reduction of potential and actual harm from a disaster, responding immediately and directly following a disaster, and recovering so that there is ongoing regeneration and resiliency for the people and communities impacted by a disaster (Ministry of Civil Defence \& Emergency Management, 2016).

Opioid Substitution Treatment (OST) is also a harm reduction approach that aims to minimise risks associated with illicit drug use, such as prevention of blood-borne diseases and criminal activity. OST medications such as suboxone and methadone need to be consumed every day to prevent uncomfortable physical and psychological withdrawals from occurring. Physical withdrawal symptoms present as uncomfortable flu-like symptoms, such as aching muscles, nausea and diarrhoea (Berry et al. 2010). Psychological and emotional withdrawal symptoms, which for some are more challenging than the physical symptoms, involve agitation, anxiety and obsessive and reoccurring thoughts of using the drug. People are only able to access OST by registering at an authorised clinic and being accepted into a programme. As controlled substances, OST medications are highly regulated, and people on OST have little agency with dosing amounts and takeaway regimes (Berry et al. 2010; Ministry of Health 2014). Access to OST is necessary for the health and wellbeing of people on OST, and their families and broader communities.

Being reliant on medications that support health and wellbeing needs to be understood as a vulnerability that requires specific DRM strategies during and after a disaster (Blake \& Lyons 2016). While people who have vulnerabilities can prepare, respond, cope and adapt to a disaster, this ability is often based on social relationships and context. A plethora of literature argues that people who are vulnerable are worse off during and following a disaster (see Baker \& Cormier 2015, Hoffman 2009, Luna 2009). Research specifically on OST highlights that in the immediate aftermath of a disaster, obtaining OST is problematic because of limited access to OST dispensing services, such as OST clinics and pharmacies with critical infrastructure damage and drug resourcing issues. To illustrate, research following Hurricane Katrina in 2005 (Bloodworth, Kevorkian, Rumbaut, \& Chiou-Tan 2007, Maxwell, Podus, \& Walsh 2009) and Sandy in 2011 (McClure, Mendoza, Duncan, Rotrosen, \& Hansen 2014) found that contact with OST treatment providers was difficult, dose amounts for people on OST were unavailable and stock levels were low. Similarly, a media report following Hurricane Harvey in 2017 outlined that people were still unable to access OST medications a week after the event (Hersher 2017). With no access to opioid treatment, some people use street drugs to avoid OST withdrawals. Using street drugs carries the risk of drug overdose, blood-borne disease and crime.

With very little knowledge about emergency planning and approaches for OST in the readiness, reduction and response phases of a disaster in Aotearoa New Zealand, this study interviewed 22 emergency management and health professionals and 21 people on OST to understand how they understood and practised DRM in the OST space. The professionals included hospital-based emergency managers, community-based emergency managers, pharmacists, OST staff, general alcohol and other drug staff and people from the Ministry of Health. The people on OST were on both suboxone and methadone and had been on a programme for between one and thirty years.

Drawing on thematic analysis to represent themes across participants' narratives, findings highlighted that the emergency management and health professionals were concerned for the health and wellbeing of people on OST after a disaster. Some considered that survival 
would be severely hindered because people might not be able to walk to safety or access food without their medication. There was also concern about co-existing mental health disorders and access to other medications such as benzodiazepines because these drugs have life-threatening withdrawal symptoms. The professional group talked about the need to ensure there would be enough OST stock after a disaster, especially if main arterial routes were closed. Emergency management plans need to include ways to verify dose amounts and obtaining opioid medication prescriptions from medical officers. At the time of the interviews, many of the OST services were yet to complete a comprehensive emergency plan, and many reported that it was difficult to make plans because of a wide-ranging number of potential disaster scenarios. All the health professionals expressed care for the health and wellbeing of people on OST.

The key themes to emerge from the narratives of people on OST included being fearful of the effects of withdrawal and how that would impact on their ability to get to safety and care for their children, or other people after a disaster. One OST client noted, 'it's not a case of someone just coming in and saying I need drugs, it's someone saying, I need a chance to survive'. All participants on OST questioned how they would access their medications if OST clinics and pharmacies were inoperable, while most of them reported that they would do whatever necessary, such as 'knocking over a doctor's [surgery and] taking their script pads' to make sure they had a way to access opioid drugs. People also said they would rob pharmacies or go to a hospital emergency department. Participants expressed a desire to be informed about emergency management planning by their clinics or pharmacists. All but one participant had not received any information on OST emergency planning, with one person saying that having information would 'be so much more reassuring if there was a plan'. They were further worried about the impact of stigma on the way emergency management people would treat them. People on OST, even though medically prescribed, experience social stigma which can have implications for people's sense of themselves and how they engage with others (Conner \& Rosen 2008, Earnshaw, Smith, \& Copenhaver 2013, Luty, Kumar \& Stagias 2010). One participant on OST said 'I'd be worried about the [emergency managers]... taking me seriously' (OST client).

This research aimed to give voice to the unique needs of people on OST following a disaster. By doing this and encouraging the emergency management field to recognise the specificity of OST it will enable inclusive DRM practices that support the safety and wellbeing of marginalised groups in a disaster scenario. Reducing vulnerability is important, as is producing preparedness plans that minimise harm to all people, their families and the broader community. OST is a successful harm reduction approach that makes a difference in the lives of people who are on the treatment; we must support them to have access to their OST in what are already chaotic and unsure disaster contexts.

\section{References}

Baker LR \& Cormier LA 2015, Disasters and vulnerable population: Evidence-based practice for helping professions. New York, NY: Springer Publishing Company.

Berry R, Townshend P, Pooley S, Deering D, Nixon L, \& Vince $K$ 2010, National opioid substitution treatment providers training programme. Wellington: Ministry of Health.

Blake D \& Lyons A 2016, Opioid substitution treatment planning in a disaster context: Perspectives from emergency management and health professionals in Aotearoa/New Zealand. International Journal of Environmental Research and Public Health, 13(1122), 2-14. doi:10.3390/ijerph13111122

Bloodworth DM, Kevorkian CG, Rumbaut E \& Chiou-Tan FY 2007, Impairment and disability in the Astrodome after Hurricane Katrina: Lessons learned about the needs of the disabled after large population movements. American Journal of Physical Medicine \& Rehabilitation, 86(9), 770-775. doi:10.1097/PHM.0b013e31813e0439

Conner KO \& Rosen D 2008, "You're nothing but a junkie": Multiple experiences of stigma in an aging methadone maintenance population. Journal of Social Work Practice in the Addictions, 8(2), 244-264. doi:10.1080/15332560802157065

Earnshaw V, Smith L \& Copenhaver M 2013, Drug addiction stigma in the context of methadone maintenance therapy: An investigation into understudied sources of stigma. International Journal of Mental Health and Addiction, 11, 110-122. doi:10.1007/s11469-012-9402-5

Hersher R 2017, Houston methadone clinics reopen after Harvey's flooding, NPR. At: https://www.npr.org/sections/healthshots/2017/09/06/548819207/houston-methadone-clinics-reopenafter-harveys-flooding

Hoffman S 2009, Preparing for disaster: Protecting the most vulnerable in emergencies University of California Davis Law Review, 42, $1491-1547$.

Luty J, Kumar P \& Stagias K 2010, Stigmatised attitudes in independent pharmacies associated with discrimination towards individuals with opioid dependence. The Psychiatrist, 34, 511-514. doi:10.1192/pb.bp.109.028951

Luna F 2009, Elucidating the concept of vulnerability: Layers not labels. International Journal of Feminist Approaches to Bioethics, 1(2), 121-139

Maxwell JC, Podus D \& Walsh D 2009, Lessons learned from the deadly sisters: Drug and alcohol treatment disruption, and consequences from Hurricanes Katrina and Rita. Substance Use \& Misuse, 44, 1681-1694. doi:10.3109/10826080902962011

McClure B, Mendoza S, Duncan L, Rotrosen J \& Hansen H 2014 , Effects of regulation on methadone and buprenorphine provision in the wake of Hurricane Sandy. Journal of Urban Health, 91(5), 9991008. doi:10.1007/s11524-014-9904-5

Ministry of Civil Defence \& Emergency Management 2016, The 4Rs: Reduction, readiness, response and recovery. At: http://www. civildefence.govt.nz/cdem-sector/cdem-framework/the-4rs/

Ministry of Health 2014, New Zealand practice guidelines for opioid substitution treatment. At: https://www.health.govt.nz/system/files/ documents/publications/nz-practice-guidelines-opioid-substitutiontreatment-apr14-v2.pdf 